\title{
Distribuição da precipitação e da erosividade mensal e anual na Flona Tapajós e seu entorno
}

\begin{abstract}
A perda de solo por erosão hídrica é uma das principais causas do declínio da produtividade de sistemas agrícolas. Seus mecanismos envolvem os processos de desprendimento, arraste e deposição do material erodido por ação do impacto das gotas de chuva em uma superfície, principalmente com solo sem cobertura vegetal. O objetivo neste trabalho foi estimar o potencial erosivo das chuvas na Flona Tapajós e seu entorno para subsidiar a adoção de práticas conservacionistas de manejo do solo e da água nessa unidade de conservação de uso sustentável. Foram utilizados dados diários de precipitação pluvial referentes aos municípios de Belterra, Santarém e Rurópolis, obtidos nas bases do Instituto Nacional de Meteorologia (INMET) e Agencia Nacional de Águas (ANA). Fez-se a estimativa do potencial erosivo das chuvas para toda série de dados em cada localidade. Também, para efeito comparativo foram analisados os períodos contendo a mesma série histórica e realizadas análises exploratórias para extrair medidas de dispersão capazes de expressar efeitos decorrentes de processos erosivos, em anos com alta contendo a mesma série histórica e realizadas análises exploratórias para extrair medidas de dispersão capazes de expressar efeitos decorrentes de processos erosivos, em anos com alta resultados de erosividade das chuvas apresentam oscilações semelhantes nos três municípios. Destaca-se o ano de 2008 foi o que apresentou o maior valor de erosividade nas três localidades, com 17.761, 20.785 e 17.567 MJ mm h1 ha-1 para os municípios de Belterra, Santarém e Rurópolis, respectivamente. Enquanto que os anos de 1992,1988 e 2010 apresentaram as menores estimativas. Anos com maior potencial erosivo na área de estudo foram classificados como extremamente chuvosos, indicando a influência de eventos de La Niña no fator erosividade das chuvas. Por outro lado, anos classificados como de redução extrema de chuva os valores de erosividade estimados foram os menores das séries históricas analisadas, apontando a influência de mecanismo como o El Niño, na redução da precipitação e, consequentemente refletindo na redução do potencial erosivo das chuvas na Flona Tapajós e seu entorno.
\end{abstract}

Palavras-chave: Potencial erosivo; Unidade de conservação; Precipitação.

\section{Distribution of monthly and annual erosion in and around Flona Tapajós}

\begin{abstract}
Soil loss due to water erosion is one of the main causes of declining productivity of agricultural systems. Its mechanisms involve the processes of detachment, dragging and deposition of the Soil loss due to water erosion is one of the main causes of declining productivity of agricultural systems. Its mechanisms involve the processes of detachment, dragging and deposition of the eroded material by the impact of raindrops on a surface, mainly with soil without vegetation cover. The objective of this work was to estimate the erosive potential of rainfall in the Tapajos
Flona and its surroundings to subsidize the adoption of conservation practices of soil and water management in this unit of conservation of sustainable use. Daily precipitation data were Flona and its surroundings to subsidize the adoption of conservation practices of soil and water management in this unit of conservation of sustainable use. Daily precipitation data were
used for the municipalities of Belterra, Santarém and Rurópolis, obtained at the National Institute of Meteorology (INMET) and National Water Agency (ANA). The rainfall erosion potential was estimated for each data series in each locality. Also, for comparative purposes, the periods with the same historical series were analyzed and exploratory analyzes were carried out to extract dispersion measures capable of expressing effects due to erosive processes, in years with high rainfall. The rainfall anomaly index was also applied to the annual totals data to identify the occurrence of extremely rainy or dry years. It is observed that the results of rainfall erosivity show similar oscillations in the three municipalities. It should be noted that 2008 presented the highest erosivity value in the three localities, with 17,761, 20,785 and 17,567 MJ mm h1 ha-1 for the municipalities of Belterra, Santarém and Rurópolis, respectively. While the years 1992, 1988 and 2010 presented the lowest estimates. Years with the rainfall erosivity factor. On the other hand, years classified as extreme rainfall, the estimated erosivity values were the lowest in the historical series analyzed, indicating the influence of the mechanism such as El Niño, in the reduction of precipitation and, consequently, in the reduction of the erosive potential of rainfall in Flona Tapajós and its surroundings.
\end{abstract}

Keywords: Erosive potential; Conservation unit; Precipitation.

Topic: Engenharia Ambiental

Reviewed anonymously in the process of blind peer.

Letícia Souza dos Santos (iD)

Universidade Federal do Pará, Brasil

http://lattes.cnpq.br/9946831897598402

http://orcid.org/0000-0002-2797-3940

Illet.santos@gmail.com

Aline Michelle da Silva Barbosa

Universidade Estadual Paulista, Brasil

http://lattes.cnpq.br/0496495918772522

http://orcid.org/0000-0001-8336-2645

aline.m.barbosa@hotmail.com

Lucieta Guerreiro Martorano (iD)

Embrapa Amazônia Oriental, Brasil

http://lattes.cnpq.br/9712490260615310

http://orcid.org/0000-0003-3893-3781

lucieta.martorano@embrapa.br
Received: 10/08/2018

Approved: 24/09/2018
José Reinaldo da Silva Cabral de Moraes (iD

Instituto Federal do Mato Grosso do Sul, Brasil

http://lattes.cnpq.br/2670721926559119

http://orcid.org/0000-0002-8567-4893

reinaldojmoraes@gmail.com

Lucas Eduardo de oliveira Aparecido

Instituto Federal do Mato Grosso do Sul, Brasil

http://lattes.cnpq.br/1805687336632729

http://orcid.org/0000-0002-4561-6760

llucasedap.bol@hotmail.com
Referencing this:

SANTOS, L. S.; BARBOSA, A. M. S.; MARTORANO, L. G.; MORAES, J. R. S. C.; APARECIDO, L. E. O.. Distribuição da precipitação e da erosividade mensal e anual na Flona Tapajós e seu entorno. Revista Ibero Americana de Ciências Ambientais, v.9, n.7, p.124-133, 2018. DOI: http://doi.org/10.6008/CBPC2179-6858.2018.007.0012 


\section{INTRODUÇÃO}

A erosão hídrica corresponde a um dos fatores que mais têm contribuído para a diminuição da produtividade de sistemas agrícolas, este processo caracterizado pelos mecanismos de desprendimento, arraste e deposição de partículas de solo é desencadeado pelo efeito da energia cinética das gotas de chuva em uma superfície sem cobertura. Apesar de ocorrer naturalmente, a erosão hídrica pode ser acentuada pela ação humana, que contribui para mudanças de uso do solo com a retirada da cobertura vegetal e, posterior conversão destes ambientes em pastagens e sistemas agrícolas (BERTONI et al., 2010).

Chuvas intensas correspondem a um dos principais fatores associados ao processo erosivo, e representam um componente de extrema importância na estimativa de perda do solo por modelos de predição, como a Equação Universal de Perda do Solo (WISCHMEIER et al., 1958). A erosividade relaciona-se exclusivamente às características físicas das chuvas, tais quais intensidade e quantidade, diâmetro de gotas e energia cinética. Diversas metodologias têm sido adotadas na avaliação deste efeito, sendo o Ei $i_{30}$, índice definido como a função entre a energia cinética da chuva em um evento de no máximo 30 minutos de intensidade, um dos mais difundidos, porém a escassez de dados de precipitação obtidos por séries de registros pluviográficos é um dos entraves a utilização deste índice (SILVA, 2004; MELLO et al., 2007).

Dessa forma, metodologias alternativas foram desenvolvidas para avaliar o efeito da erosividade mesmo em regiões com escassez de dados obtidos a partir de pluviogramas. Cassol et al. (2008) e Oliveira et al. (2012) relacionaram o $\mathrm{Ei}_{30}$ com o Coeficiente da chuva (Rc) e obtiveram elevados valores de correlação. $\mathrm{O}$ Rc proposto por Renard et al. (1994) representa o Índice de Fournier, indicando que este índice é capaz de fornecer informações a partir do registro dos totais diários de precipitação, dados que podem ser mais facilmente obtidos em estações meteorológicas. Com base na análise desses indicadores é possível avaliar se existem zonas frágeis ao processo erosivo, assim como a estimativa de época do ano em que chuvas erosivas podem ocorrer com maior frequência podem subsidiar a adoção de manejo conservacionista do solo, sendo uma ferramenta importante para implantação de programas e práticas que visem a minimização dos efeitos negativos relacionados à perda de solo em sistemas agrícolas (SILVA, 2004; MARTORANO et al., 2016).

Em áreas protegidas o monitoramento e a identificação de possíveis fragilidades relacionadas a erosão é indispensável para a manutenção destas áreas frente as pressões antrópicas decorrentes da ocupação em seu entorno. Destaca-se que cerca de $46 \%$ do território amazônico encontra-se sob a forma de áreas legalmente protegidas, sendo que entre as Unidades de Conservação de Uso Sustentável na região destaca-se a Flona Tapajós, localizada na porção oeste do estado do Pará. Sua área e zona de amortecimento abrangem os municípios de Belterra, Santarém, Rurópolis, Aveiro, Placas e Mojuí dos Campos. Vale ressaltar que esta Unidade de conservação (UC) vêm sofrendo pressões antrópicas decorrentes da proximidade de duas importantes rodovias (BR-230 - Transamazônica e BR-163 - Santarém-Cuiabá), fazendo fronteira com o polo graneleiro do Tapajós (LISBOA, 2015; NASCIMENTO et al., 2014). O objetivo da pesquisa foi estimar o potencial erosivo das chuvas e avaliar a fragilidade à erosão na Floresta Nacional do Tapajós de modo a 
subsidiar a adoção de práticas conservacionistas de uso de solo e de água para minimizar a ocorrência de processos erosivos.

\section{MATERIAIS E MÉTODOS}

Dados de precipitação diária foram obtidos a partir de estações pluviométricas localizadas em regiões próximas a área de estudo disponibilizadas nas bases de dados da Agência Nacional de Águas (ANA) e Instituto Nacional de Meteorologia (INMET). A partir da análise exploratória dos dados foi possível selecionar as estações com maior homogeneidade de dados de precipitação e com registro de no mínimo 30 anos de chuvas diárias. Desta forma foram escolhidas as estações correspondentes aos municípios de Belterra (Latitude: -2,63; Longitude: -54,95), Santarém (Latitude: -1,1788; Longitude: -53,599) e Rurópolis (Latitude:4,08; Longitude: -54,90), como pode ser observado na Figura 1.
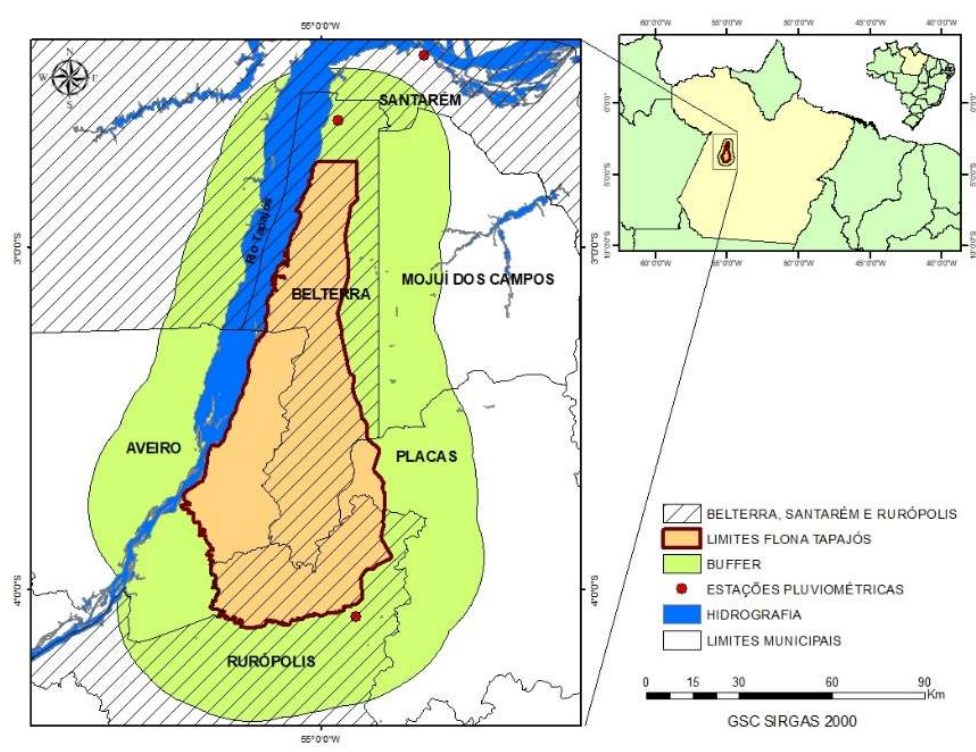

Figura 1: Localização referente à Floresta Nacional do Tapajós e estações pluviométricas utilizadas na pesquisa.

Após a obtenção dos dados de precipitação pluviométrica extraiu-se uma série de dados homogênea referente aos anos de 1986 a 2017, totalizando 31 anos de análise para cada estação. Com base nos dados de precipitação diária foram calculados os totais mensais e anuais para cada série histórica, o que permitiu a obtenção do Índice de Founier ou Coeficiente de chuva (Rc), o qual está representado pela equação 1.

$$
\mathrm{Rc}=\frac{\mathrm{p}^{2}}{\mathrm{P}} \quad \text { Equação } 1
$$

Em que RC representa o Coeficiente de chuva, $\mathrm{p}$ expressa a precipitação média mensal $(\mathrm{mm})$ e $\mathrm{P}$ a precipitação anual $(\mathrm{mm})$.

A partir dos dados obtidos com coeficiente de chuva (Rc) foi possível calcular o $\mathrm{El}_{30}$, que corresponde ao produto da energia cinética de chuvas erosivas $(\mathrm{E})$ com alta intensidade em um período de máxima em 30 minutos $\left(I_{30}\right)$, a correlação entre o $\mathrm{Ei}_{30}$ e o Rc foi proposta por (), e está representado pela (Equação 2).

$$
\mathrm{El}_{30}=321,5+36,2 * \mathrm{Rc} \quad \text { Equação } 2
$$

A obtenção do índice de anomalia de chuva para cada município foi realizado adotando a metodologia aplicada por (ROOY, 1965), utilizando as Equações 3 e 4. 


$$
\begin{array}{ll}
\mathrm{IAC}=3^{*}\left(\frac{\text { PRP-PRPm }}{\mathrm{x}-\mathrm{PRPm}}\right) & \text { Equação } 3 \\
\mathrm{IAC}=-3^{*}\left(\frac{\text { PRP-PRPm }}{\mathrm{y}-\mathrm{PRPm}}\right) & \text { Equação } 4
\end{array}
$$

Em que, IAC é o índice de anomalia de chuva; PRP $(\mathrm{mm})$ é a precipitação observada; PRPm (mm) expressa a precipitação média; $x(\mathrm{~mm})$ é a média dos dez maiores valores de precipitação observados; y ( $\mathrm{mm}$ ) é a média dos dez menores valores de precipitação observados.

Após o cálculo dos índices de anomalias de chuva foi realizada a sua classificação de acordo com as categorias descritas na Tabela 1, enfatizando os eventos extremos para cada série.

Tabela 1: Classificação do índice de anomalia de chuva.

\begin{tabular}{|l|l|}
\hline IAC & CLASSIFICAÇÃO \\
\hline$\geq 4,00$ & Extremamente chuvoso \\
\hline 3,00 a 3,99 & Elevada quantidade de chuva \\
\hline 0,5 a 1,99 & Baixa quantidade de chuva \\
\hline$-0,49$ a 0,49 & Normal \\
\hline$-1,990,5$ & Redução suave de chuva \\
\hline$-2,002,99$ & Moderada redução de chuva \\
\hline$-3,00$ a $-3,99$ & Significativa redução de chuva \\
\hline$\leq-4,00$ & Redução extrema de chuva \\
\hline
\end{tabular}

Fonte: Adaptado de Rooy (1965).

O cálculo do período de retorno e probabilidade de ocorrência da erosividade anual dos municípios foram determinados usando as Equações 5 e 6, conforme método aplicado por Schwab et al. (1981).

$$
\begin{aligned}
& T=\frac{(\mathrm{N}+1)}{\mathrm{m}} \quad \text { Equação } 5 \\
& \operatorname{Pr}=\frac{100}{\mathrm{~T}} \quad \text { Equação } 6
\end{aligned}
$$

Sendo que T equivale ao período de retorno em anos no qual o índice de erosividade pode ser igualado ou superado; $\mathrm{n}$ corresponde ao número de anos de registro de dados da série estudada; $\mathrm{m}$ é o número de ordem da erosividade da série considerada quando colocada em ordem decrescente e Pr é a probabilidade de ocorrência do índice de erosividade em percentual (\%).

\section{RESULTADOS}

Nas Figuras 2,3 e 4 observaram-se os valores de precipitação e erosividade anuais entre os anos de 1987 a 2017 para os municípios de Belterra, Santarém e Rurópolis, respectivamente. Os maiores valores de precipitação obtidos para o município de Belterra ocorreram nos anos de 2009, 2013 e 1989, anos em que a precipitação no município alcançou valores próximos a $2.400 \mathrm{~mm}$. Os maiores valores do índice de erosividade $\left(\mathrm{El}_{30}\right)$ estimados em Belterra ocorreram nos anos de 2008, 2006 e 2009, nesses anos os valores de erosividade foram superiores a $15.000 \mathrm{MJ} \mathrm{mm} \mathrm{ha}^{-1} \mathrm{~h}^{-1}$. Os anos de 1992 e 1998 se destacaram como anos de baixa oferta pluvial, coincidindo com os menores valores de erosividade estimados na série histórica analisada (Figura 2).

No município de Santarém (Figura 3), analisando a série histórica de precipitação pluvial observouse valores mais expressivos nos anos de 2008, 1988 e 2000, com destaque para o ano de 2008, que atingiu o valor de $3.054 \mathrm{~mm}$. Coincidindo com os valores de precipitação, o ano que apresentou maior estimativa de erosividade da série histórica foi o ano de 2008, seguido pelos anos de 2009 e 2000 . O menor valor de 
precipitação e erosividade estimada ocorreu no ano de 1992, ano em que a precipitação pluvial anual atingiu o valor de $948 \mathrm{~mm}$ e a erosividade estimada foi de $9.526 \mathrm{MJ} \mathrm{mm} \mathrm{ha}^{-1} \mathrm{~h}^{-1}$.

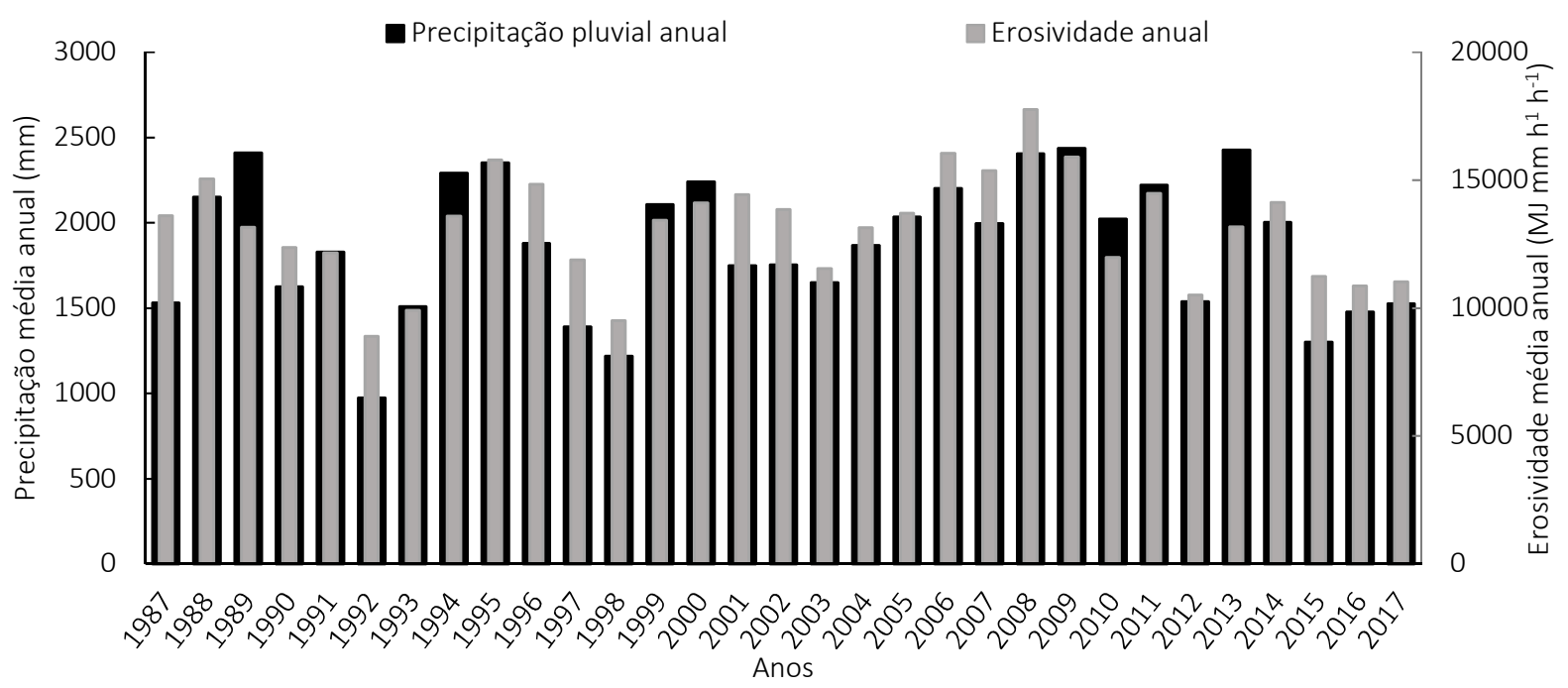

Figura 2: Precipitação e erosividade média anuais de Belterra.

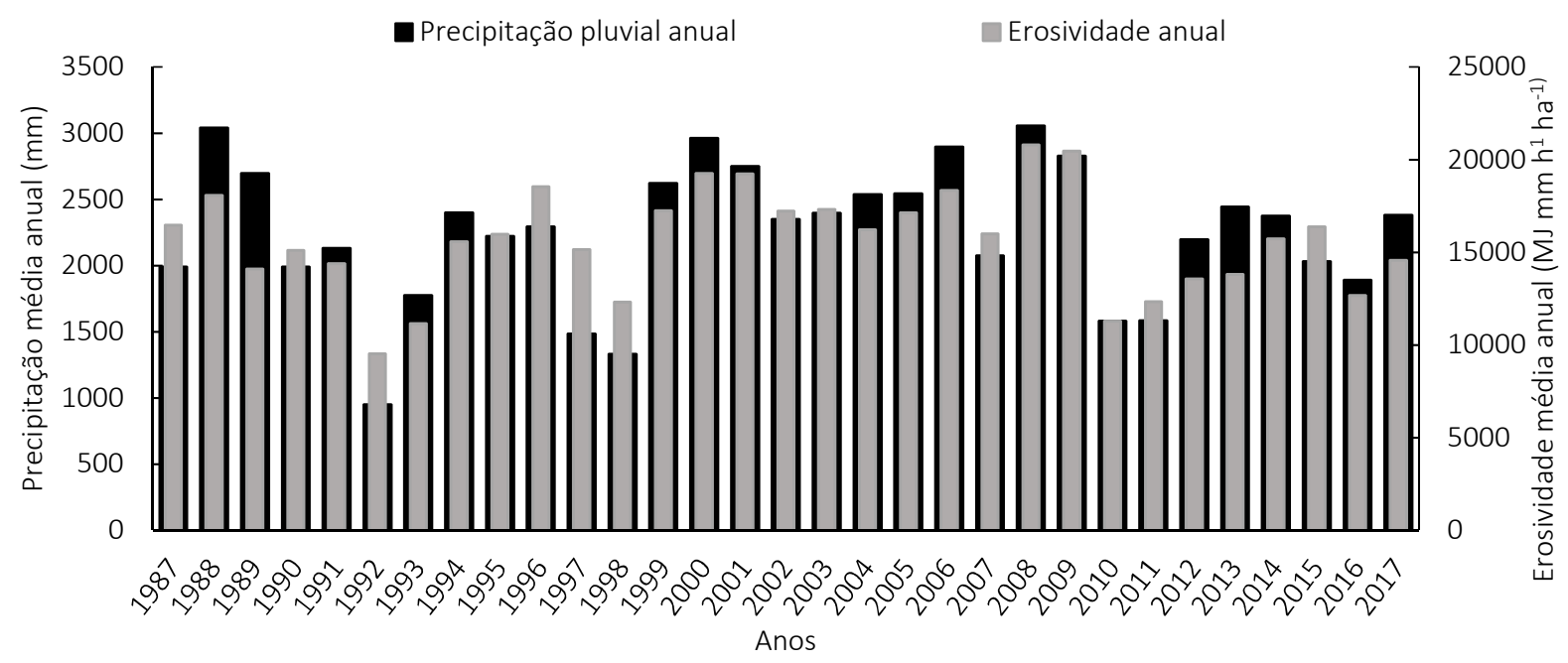

Figura 3: Precipitação e erosividade média anual de Santarém.

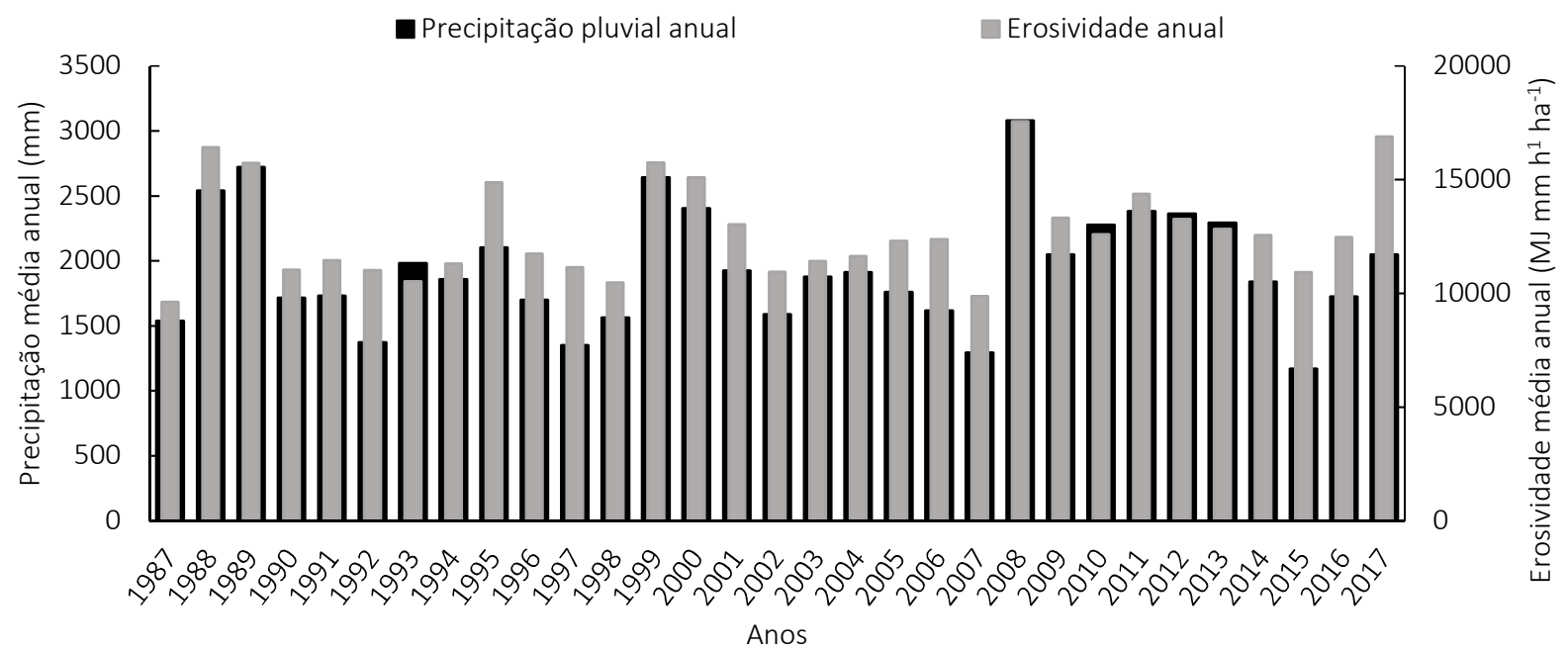

Figura 4: Precipitação e erosividade média anual de Rurópolis. 
Já para o município de Rurópolis verificou-se valores elevados de precipitação nos anos de 2008, 1989 e 1999, enquanto em relação a erosividade anual estimada o ano de 2008 continuou sendo o ano de maior destaque com erosividade de 17.567 MJ mm ha-1 $\mathrm{h}^{-1}$. Os anos que apresentaram os menores valores de precipitação foram 2015, 2007 e 1997, e as menores estimativas de erosividade ocorreram em 1998, 2007 e 1987 (Figura 4).

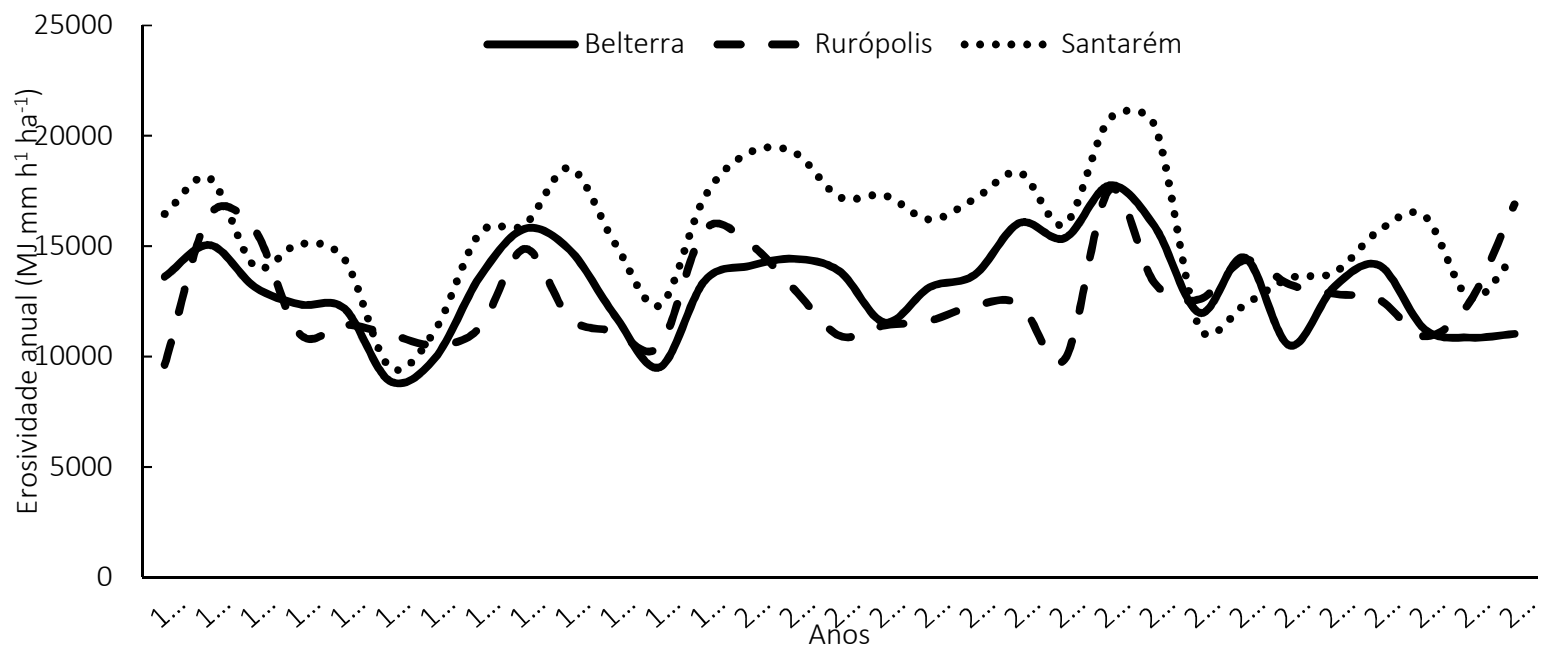

Figura 5 Comparação entre as erosividades anuais dos municípios de Belterra, Rurópolis e Santarém.

Tabela 2: Período de retorno e probabilidade de ocorrência da erosividade anual nos municípios de Belterra, Santarém e Rurópolis.

\begin{tabular}{|c|c|c|c|c|c|c|c|c|}
\hline & Belterra & & Santarém & & urópolis & & & \\
\hline Ano & $\begin{array}{c}\text { Índice de } \\
\text { erosividade (Ei30) } \\
\text { Mj mm ha- }{ }^{-1} \mathrm{~h}^{-1}\end{array}$ & Ano & $\begin{array}{c}\text { Índice de } \\
\text { erosividade (Ei30) } \\
\text { Mj mm ha- }{ }^{1} \mathrm{~h}^{-1}\end{array}$ & Ano & $\begin{array}{c}\text { Índice de } \\
\text { erosividade (Ei3O) } \\
\text { Mj mm ha- }{ }^{-1} \mathrm{~h}^{-1}\end{array}$ & $\begin{array}{l}\text { Número de } \\
\text { ordem }(m)\end{array}$ & $\begin{array}{l}\text { Período de } \\
\text { retorno }(T) \\
\text { (Anos) }\end{array}$ & $\begin{array}{c}\text { Probabilidade } \\
\text { de ocorrência } \\
\text { (\%) }\end{array}$ \\
\hline 2008 & 17761,6 & 2008 & 20785,0 & 2008 & 17567,3 & 1 & 32 & 3,13 \\
\hline 2006 & 16057,1 & 2009 & 20471,2 & 2017 & 16900,2 & 2 & 16 & 6,25 \\
\hline 2009 & 15901,8 & 2000 & 19247,1 & 1988 & 16424,9 & 3 & 10,7 & 9,38 \\
\hline 1995 & 15791,9 & 2001 & 19236,4 & 1999 & 15745,5 & 4 & 8 & 12,50 \\
\hline 2007 & 15369,4 & 1996 & 18551,1 & 1989 & 15733,3 & 5 & 6,4 & 15,63 \\
\hline 1988 & 15054,2 & 2006 & 18337,3 & 2000 & 15107,3 & 6 & 5,3 & 18,75 \\
\hline 1996 & 14833,2 & 1988 & 18077,1 & 1995 & 14885,3 & 7 & 4,6 & 21,88 \\
\hline 2011 & 14489,8 & 2003 & 17303,7 & 2011 & 14367,6 & 8 & 4 & 25,00 \\
\hline 2001 & 14429,3 & 1999 & 17241,5 & 2009 & 13327,9 & 9 & 3,6 & 28,13 \\
\hline 2014 & 14124,1 & 2002 & 17223,1 & 2012 & 13268,6 & 10 & 3,2 & 31,25 \\
\hline 2000 & 14109,0 & 2005 & 17145,0 & 2001 & 13029,3 & 11 & 2,9 & 34,38 \\
\hline 2002 & 13859,4 & 1987 & 16460,1 & 2013 & 12839,8 & 12 & 2,7 & 37,50 \\
\hline 2005 & 13705,0 & 2015 & 16368,2 & 2010 & 12597,0 & 13 & 2,5 & 40,63 \\
\hline 1987 & 13618,0 & 2004 & 16212,1 & 2014 & 12566,8 & 14 & 2,3 & 43,75 \\
\hline 1994 & 13601,2 & 2007 & 15987,8 & 2016 & 12469,1 & 15 & 2,1 & 46,88 \\
\hline 1999 & 13434,9 & 1995 & 15981,8 & 2006 & 12375,3 & 16 & 2 & 50,00 \\
\hline 2013 & 13181,0 & 2014 & 15733,7 & 2005 & 12313,8 & 17 & 1,9 & 53,13 \\
\hline 1989 & 13157,9 & 1994 & 15584,2 & 1996 & 11744,4 & 18 & 1,8 & 56,25 \\
\hline 2004 & 13138,6 & 1997 & 15152,3 & 2004 & 11627,7 & 19 & 1,7 & 59,38 \\
\hline 1990 & 12369,3 & 1990 & 15106,1 & 1991 & 11444,3 & 20 & 1,6 & 62,50 \\
\hline 1991 & 12163,8 & 2017 & 14563,2 & 2003 & 11415,1 & 21 & 1,5 & 65,63 \\
\hline 2010 & 11985,1 & 1991 & 14400,5 & 1994 & 11307,5 & 22 & 1,5 & 68,75 \\
\hline 1997 & 11879,8 & 1989 & 14095,6 & 1997 & 11143,4 & 23 & 1,4 & 71,88 \\
\hline 2003 & 11542,7 & 2013 & 13817,0 & 1990 & 11029,2 & 24 & 1,3 & 75,00 \\
\hline 2015 & 11246,3 & 2012 & 13559,5 & 1992 & 11010,4 & 25 & 1,28 & 78,13 \\
\hline 2017 & 11034,3 & 2016 & 12665,7 & 2002 & 10942,8 & 26 & 1,2 & 81,25 \\
\hline 2016 & 10859,8 & 2011 & 12349,4 & 2015 & 10923,4 & 27 & 1,2 & 84,38 \\
\hline 2012 & 10505,1 & 1998 & 12316,5 & 1993 & 10525,8 & 28 & 1,1 & 87,50 \\
\hline 1993 & 9914,4 & 2010 & 11293,5 & 1998 & 10478,0 & 29 & 1,1 & 90,63 \\
\hline 1998 & 9516,3 & 1993 & 11165,9 & 2007 & 9875,4 & 30 & 1,1 & 93,75 \\
\hline 1992 & 8899,2 & 1992 & 9526,0 & 1987 & 9620,7 & 31 & 1,0 & 96,88 \\
\hline
\end{tabular}



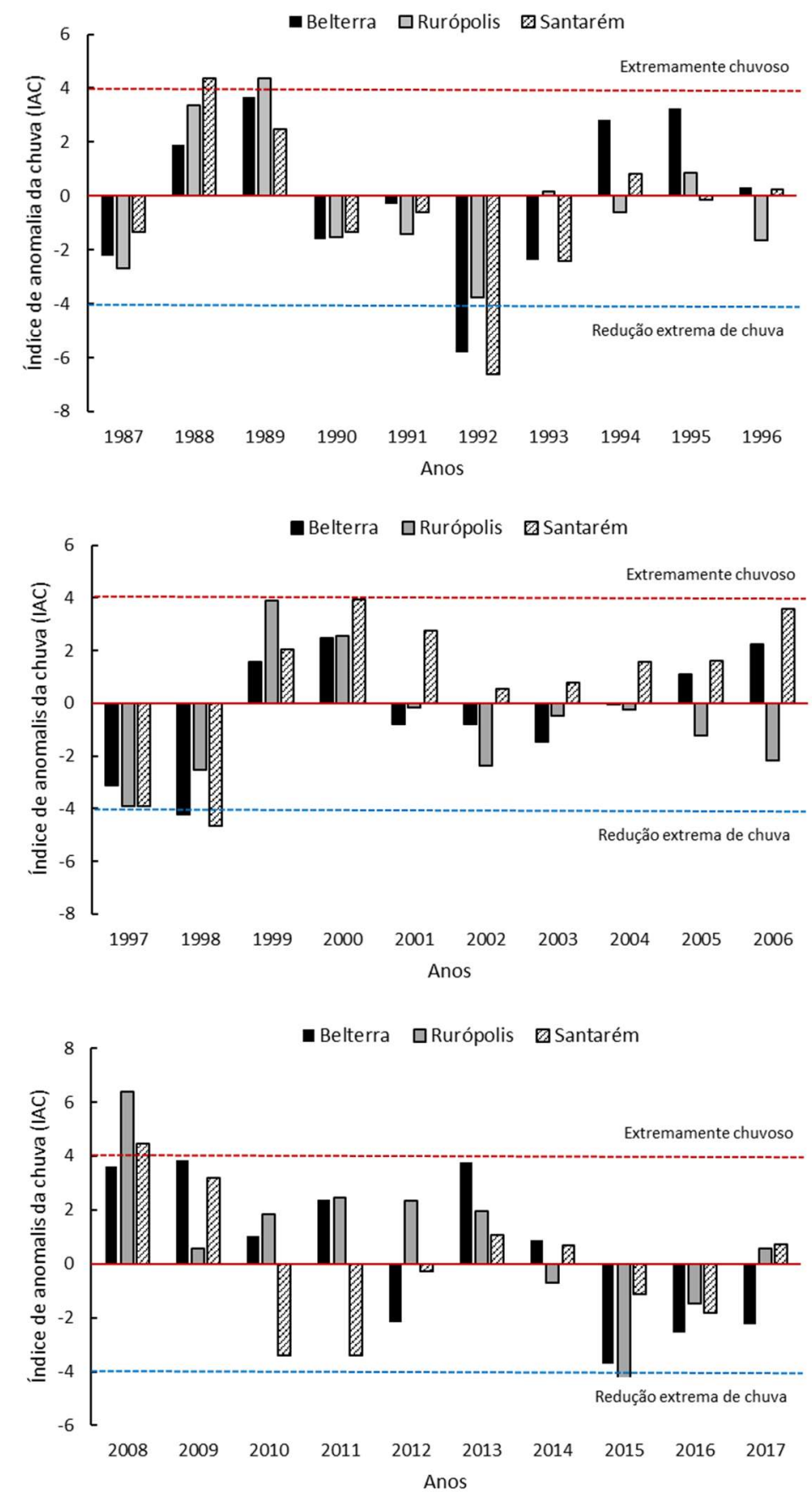

Figura 6: Índices de anomalia das chuvas (IAC) para os municípios de Belterra, Rurópolis e Santarém.

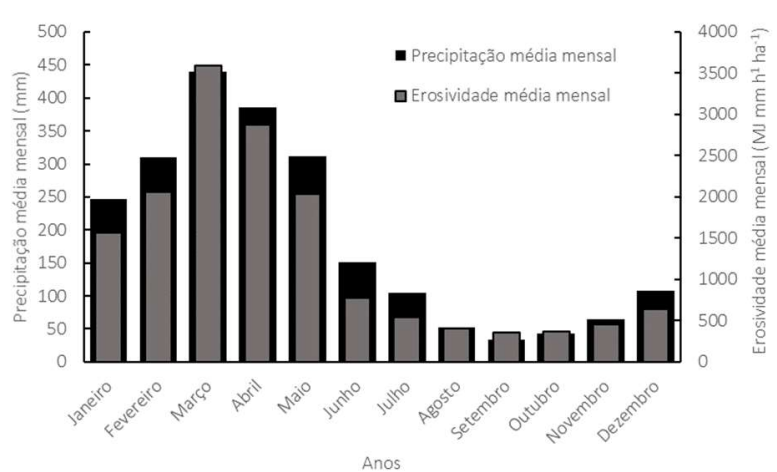

Figura 7: Precipitação e erosividade média mensal para o município de Santarém.

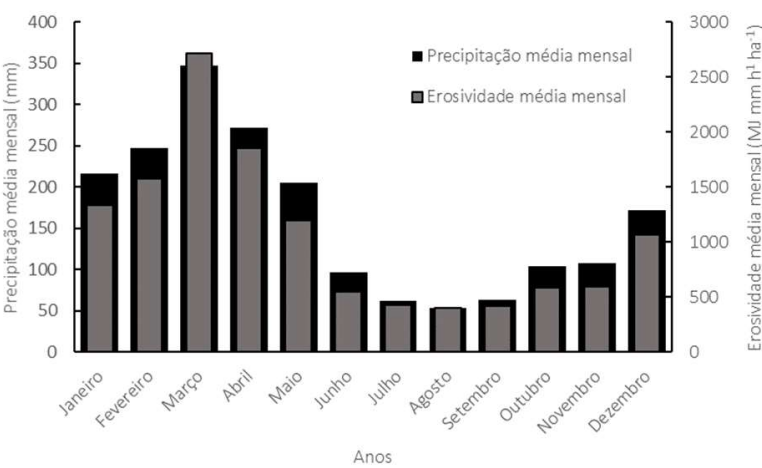

Figura 8: Precipitação e erosividade média mensal para o município de Rurópolis. 


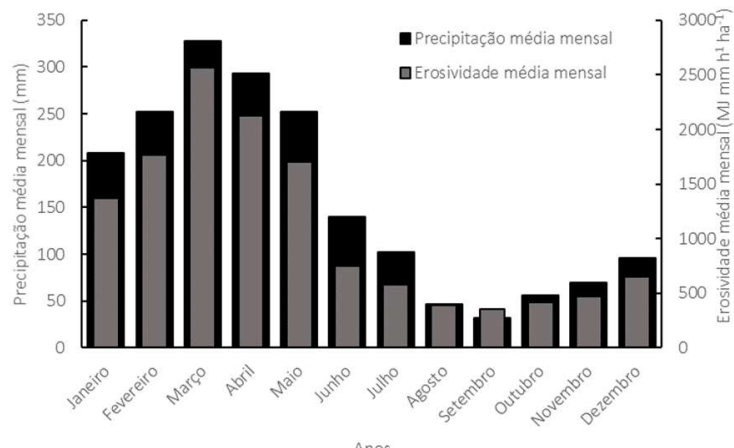

Figura 9: Precipitação e erosividade média mensal para o município de Belterra.

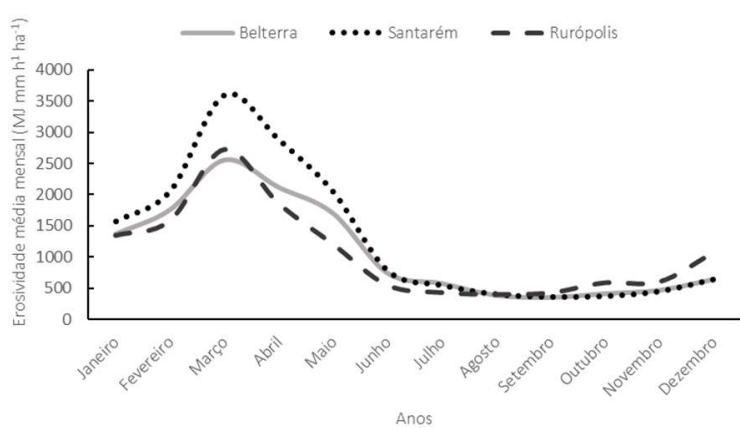

Figura 10: Comparação entre as erosividades anuais dos municípios de Beltera, Rurópolis e Santarém.

\section{DISCUSSÃO}

Os elevados índices de erosividade estimados para os municípios de Belterra, Santarém e Rurópolis estão em concordância com os valores estimados para a região, Mello et al. (2013), analisando a erosividade média anual das regiões brasileiras constataram que a região norte, devido ao elevado volume de precipitação em relação as outras regiões, apresentou elevados valores de erosividade, com médias anuais em torno de $12.000 \mathrm{MJ} \mathrm{mm} \mathrm{h}^{1}$ ha $^{-1}$. Oliveira Jr et al. (1990), estudando a série histórica de 1973 a 1983 para a cidade de Manaus, estimaram valores de erosividade cuja média dos anos correspondeu a 14.139,6 MJ mm $\mathrm{h}^{1} \mathrm{ha}^{-1}$, com valor máximo no ano de 1981 que alcançou $17.709,5 \mathrm{MJ} \mathrm{mm} \mathrm{h}^{1} \mathrm{ha}^{-1}$.

Comparando os valores estimados de erosividade para os três municípios que compõem a área de entorno da Flona Tapajós (Figura 5), foi possível observar oscilações semelhantes de erosividade na série histórica analisada, com destaque para o ano de 2008 com o maior valor estimado nos três municípios, com valores de 17.761, 20.785 e $17.567 \mathrm{MJ} \mathrm{mm} \mathrm{h}^{1}$ ha $^{-1}$ em Belterra, Santarém e Rurópolis, respectivamente. Enquanto que os anos de 1992, 1988 e 2010 destacaram-se como anos de baixos valores de precipitação pluvial e consequentemente menores estimativas de erosividade para a série histórica referente às localidades analisadas.

Com base nos dados apresentados na Tabela 2, foi possível observar os valores de erosividade anual classificado em ordem decrescente para cada município, assim como seus respectivos valores de Período de retorno $(T)$, período em que este valor de erosividade poderia ser repetido ou igualado e probabilidade de ocorrência deste evento (Pr) em porcentagem (\%). Como destacado pelos resultados anteriores o ano de 2008 foi o que apresentou maior valor de erosividade, portanto o período de retorno estimado para este evento foi de 32 anos, com uma probabilidade de ocorrência de 3,13 \%.

Com a aplicação do Índice de anomalias de chuva (IAC) (Figura 6) foi possível observar a ocorrência de anos extremamente chuvosos e secos, seguindo a classificação proposta por ROOY, 1965. O índice aplicado ao município de Belterra não indicou a ocorrência de anos extremamente chuvosos no período de 1987 a 2017 correspondente a série histórica analisada, enquanto que para o município de Rurópolis os anos de 1989 e 2008 tiveram essa classificação. Para o município de Santarém eventos extremos de chuva ocorreram nos anos de 1988, 1998 e 2008. Como esperado, o ano de 2008 se destacou como um ano extremamente chuvoso, apesar de não ser observada esta classificação para o município de Belterra, o IAC 
obtido nos três municípios estudados foram considerados altos, com valores próximos ou superiores a 4 . Anos classificados como extremamente chuvosos possivelmente podem ser associados aos efeitos La Niña na região (ÁVILA et al., 2013).

Os anos de 1992 e 1998 foram classificados como anos com redução extrema de chuva para os municípios de Belterra e Santarém, no município de Rurópolis o IAC não alcançou o valor de (-4) nesses anos, esta classificação foi obtida apenas para o ano de 2015. Anos enquadrados na classe de secos por redução estrema de chuva podem ser associados aos fenômenos de bloqueio na circulação da atmosfera provocados pelo El niño (ARAÚJO et al., 2013).

Os municípios analisados apresentaram comportamento semelhante em grande parte dos anos os quais foram aplicados o IAC. No entanto, para o município de Rurópolis nos anos de 1993,1996, 2005, 2006, 2014 o Índice de anomalia de chuva apresentou um padrão diferente dos demais municípios, fato que pode ser atribuído a maior distância geográfica de Rurópolis em relação a Santarém e Belterra, a localização deste município na porção mais ao sul da Flona Tapajós possibilita a influência de outros fenômenos climáticos que podem afetar o IAC.

Os valores de erosividades médias mensais estimados nos permite identificar o comportamento destes eventos ao longo do ano, assim pode-se reconhecer as épocas do ano com menor ou maior potencial erosivo em relação às chuvas. Na figura 7, em que estão representadas as estimativas das erosividades médias mensais para o município de Santarém, observa-se que nos meses de abril e principalmente março elevados valores de erosividade, enquanto que nos meses de julho a setembro foram obtidos menores valores durante a série histórica analisada, comportamento similar foi identificado nos gráficos referentes aos municípios de Rurópolis (Figura 8) e Belterra (Figura 9).

Na figura 10, observa-se de forma mais clara a oscilação semelhante ao longo do ano em relação à estimativa de erosividade para os três municípios, a identificação dos meses em que a erosividade ocorre de uma forma mais intensa nos municípios ao entorno da Flona Tapajós pode contribuir para nortear ações que visem o manejo conservacionista do solo, principalmente em áreas declivosas ou fragilizadas pela falta de cobertura.

Tanto nas análises de erosividades médias anuais quanto mensais, observou-se que as estimativas das três regiões estudadas possuem oscilações correspondentes, sendo assim, podem ser utilizadas para representar a região pertencente a Flona Tapajós, apesar da escassez de dados de precipitação nos demais municípios que integram esta região, tais como Aveiro e Placas.

\section{CONCLUSÕES}

O comportamento da erosividade das chuvas nos municípios de Belterra, Santarém e Rurópolis foi observado de modo semelhante nos três municípios, indicando que estes podem ser utilizados para representar de modo satisfatório a Floresta Nacional do Tapajós e sua área de entorno. A homogeneidade das séries históricas analisadas torna possível a identificação de eventos extremos ao longo dos anos e a observação deste fenômeno em escala mensal. 
A estimativa de erosividade mensal e anual e sua correlação com coeficiente de chuva e índice de anomalias pode nortear ações preventivas de manejo e conservação do solo, evitando que perdas erosivas prejudiquem de modo severo a produtividade e estabilidade de sistemas pertencentes a unidades de conservação como a Flona Tapajós, e áreas pertencentes ao seu entorno, caracterizadas como áreas que sofrem elevadas pressões de origem antrópica.

\section{REFERÊNCIAS}

ARAUJO, R. G.; ANDREOLI, R. V.; CANDIDO, L. A.; KAYANO, M. T.; SOUZA, R. A. F.. A influência do evento El Niño: Oscilação Sul e Atlântico Equatorial na 21 precipitação sobre as regiões norte e nordeste da América do Sul. Acta Amazônia, v.43, n.4, p.469-480, 2013.

ÁVILA; P. L. R.; SOUZA; E. B.; PINHEIRO A. N.. Simulação da precipitação sazonal com o Regcm4 sobre o estado do Pará para anos de El Niño e La Niña. Revista Brasileira de Geografia Física, v.6, n.5, p.1316-1335, 2013.

BERTONI, J.; LOMBARDI NETO, F.. Conservação do solo. 7 ed. São Paulo: Ícone, 2010.

CASSOL, E. A.; FOLETTO ELTZ, F. L.; MARTINS, D.; LEMOS, A. M.; SILVA DE LIMA, V.; CAMARA BUENO, A.. Erosividade, padrões hidrológicos, período de retorno e probabilidade de ocorrência das chuvas em São Borja, RS. Revista Brasileira de Ciência do Solo, v.32, n.3, p.1239-1251, 2008.

MELLO, C. R.; SÁ, M. A. C.; CURI, N.; MELLO, J. M.; VIOLA, M. R.; SILVA, A. M.. Erosividade mensal e anual da chuva no Estado de Minas Gerais. Pesquisa Agropecuária Brasileira, v.42, n.4, p.537-545, 2007.

LISBOA, L. S. S.. Padrões de uso e cobertura do solo na Floresta Nacional do Tapajós e seu entorno. Tese (Doutorado) - Universidade de São Paulo, Piracicaba, 2015.

MELLO, C. D.; VIOLA, M. R.; BESKOW, S.; NORTON, L. D.. Multivariate models for annual rainfall erosivity in Brazil. Geoderma, v.202-203, p.88-102, 2013.
NASCIMENTO, N. C. C.; MARTORANO, L. G.; BELTRAO, N. E.; LISBOA, L. S. S.; SODRE, T.; MELO, D.. Panorama espaço temporal de fatores de mudanças econômica, social e ambiental na Amazônia: estudo de caso Flona Tapajós. Seminário de Pesquisas Científicas da Floresta Nacional do Tapajós, Santarém, 2014.

OLIVEIRA JUNIOR, R. C.; MEDINA, B. F.. A erosividade das chuvas em Manaus (AM). Rev. Bras. Ciênc. Solo, v.14, p.235239, 1990.

OLIVEIRA, P. T. S.; RODRIGUES, D. B. B.; SOBRINHO, T. A.; CARVALHO, D. F.; PANACHUKI, E. P.. Spatial variability of the rainfall erosive potential in the state of Mato Grosso do Sul, Brazil. Engenharia Agrícola, v.32, p.69-79, 2012.

RENARD, K. G.; FREIMUND, J. R.. Using monthly precipitation data to estimate the R-factor in the revised USLE. Journal of hydrology, v.157, n.1-4, p.287-306, 1994.

ROOY, M. P.. A rainfall anomaly index independent of time and space. Notos, Pretoria, v.14, p.43-48, 1965.

SCHWAB, G. O.; FREVEET, R. K.; EDMINSTER, T. W.; BARNES, K. K.. Soil and water conservation engineering. 3 ed. New York: Jhon Wiley \& Sons, 1981.

SILVA, A. M.. Rainfall erosivity map for Brazil. Catena, v.57, n.3, p.251-259, 2004.

WISCHMEIER, W. H.; SMITH, D. D.. Rainfall energy and its relationship to soil loss. Eos, Transactions American Geophysical Union, v.39, n.2, p.285-291, 1958.

A CBPC - Companhia Brasileira de Produção Científica (CNPJ: 11.221.422/0001-03) detém os direitos materiais desta publicação. Os direitos referem-se à publicação do trabalho em qualquer parte do mundo, incluindo os direitos às renovações, expansões e disseminações da contribuição, bem como outros direitos subsidiários. Todos os trabalhos publicados eletronicamente poderão posteriormente ser publicados em coletâneas impressas sob coordenação da Sustenere Publishing, da Companhia Brasileira de Produção Científica e seus parceiros autorizados. Os (as) autores (as) preservam os direitos autorais, mas não têm permissão para a publicação da contribuição em outro meio, impresso ou digital, em português ou em tradução. 